\title{
Understanding the Dark Sides of Alternative Economies to Maximize Societal Benefit
}

\author{
Forrest Watson, ' $[$ and Ahmet Ekici²
}

\begin{abstract}
Alternative economies can significantly contribute to societal flourishing, but the potential dark sides should also be considered. As shared commitments are the foundation of alternative economies, we draw on related literature to conceptualize various types of dark sides of an alternative economy. While less prominent than the well-being outcomes, we present qualitative data of when the participants of one alternative food network experienced disappointment, burnout, guilt, or division. Comparing with the dark sides gleaned from other studies on alternative economies, we present a framework for evaluating the dark sides in alternative economies. Dark sides can be on a continuum from the micro level to the macro level, as well as more likely to threaten the continuance of alternative economies or societal well-being. We offer recommendations to guard against the vulnerabilities of alternative economies for their continued growth and impact, as well as discuss the implications for research on marketing systems failure.
\end{abstract}

\section{Keywords}

shared commitments, well-being, marketing systems, macromarketing, alternative economies, dark side of alternative economies

\section{Introduction}

There is growing momentum in the scholarship on alternative economies in response to financial crisis and uneven value creation through the predominant economic system. Criticism of capitalism (Gibson-Graham 2006), distributive justice (Laczniak and Santos 2011), and degrowth (Lloveras and Quinn 2017) exemplify the range of scholarship in the search for alternative forms of value creation between human beings (Haase, Becker, and Pick 2018). Macromarketers, concerned with the functioning and outcomes of marketing systems (Layton 2007), are interested in alternative economies as they may compensate for some of the drawbacks of traditional marketing systems in contributing to societal well-being and sustainability (Layton 2009; Mittelstaedt et al. 2014). Although alternative economies hold promise for improving well-being of market actors, this paper aims to identify drawbacks that could limit their societal benefit.

The notion of alternative economies is best articulated in contrast to the predominant economy in terms of its (1) means and its (2) end. Whereas the traditional commercial market tends to be associated with self-interested separate actors undertaking exchanges for material gain, alternative economic movements aim to resocialize economic relations and provide opportunities "where ethical economic decisions can be made around recognized forms of interdependence" (Gibson-Graham 2006 , p. 81). The intended end is minimizing economic domination and exploitation of subordinated local subjects.
Gibson-Graham (2006) advocate the means of "politics of collective action" with the end of "a new kind of economic reality" (p. xxxvi). Day (2005) urges working from affinity in the pursuit of emancipation. Taken together, alternative economies may be present when actors are not exploited, profit maximization is not all-important, local subjects are empowered, and human conditions are improved.

Of particular interest to this research is shared commitments as the foundation of alternative economies. Campana, Chatzidakis, and Laamanen (2014) posit that "Alternative economies rest on shared commitments to minimize economic domination and exploitation and thereby alleviate the subordinated position of local subjects." The primary means for an alternative economy is shared commitments. We follow Watson and Ekici's (2017) definition of shared commitments as "a choice of a course of action in common with others... when actors take collective action toward a common goal for the long-term welfare of all" (Watson and Ekici 2017, p. 207). For an alternative economy to best achieve its goals, there should be shared

\footnotetext{
'Middle East Technical University, Ankara, Turkey

${ }^{2}$ Bilkent University, Ankara, Turkey

Corresponding Author:

Forrest Watson, Middle East Technical University, Ankara 06800, Turkey. Email: forrest@metu.edu.tr
} 
commitments among all of the involved actors, including owners, producers, and consumers.

The recent Journal of Macromarketing Special Issue on Alternative Economies is a strong evidence for the increased attention on the topic. The Special Issue provides direction to emerging work on alternative economies "aiming to empower their subjects and to provision community-based and broader social-environmental welfare" (p. 126), including the paradigms used, the guiding institutional logics, and the implications (Campana, Chatzidakis, and Laamanen 2017). The collection of work challenges the predominant focus of economic growth and profit, promising instead wider access to resources, localized development, and improved human and environmental conditions. The articles assembled provide a convincing argument about the value of alternative economies and their role in improving the human conditions, but generally overlook potentially detrimental outcomes that can also be generated through alternative economies. While Watson and Ekici (2017), one of the contributions in the Special Issue, showed how shared commitments led to well-being improvements in an alternative food network, the article falls short in addressing the ill-being outcomes that may result from shared commitments. There may be many advantages to a network founded on shared commitments, but ill-being and well-being outcomes may be present simultaneously (Ekici et al. 2018).

Although the contrasts between mainstream and alternative economies (e.g. Table 1, adapted from Gibson-Graham 2006, p. 126) are convincing about the need for alternatives, it is too rosy a contrast to describe the mainstream economy as amoral and crisis-ridden, while the alternative economy is ethical and harmonious. The existing body of macromarketing knowledge provides scant recognition of when such an ethical approach may have unintended negative consequences and provoke disharmony. Our aim in this paper is to underline various forms of dark sides that if not recognized and handled may undermine the value created through alternative economies.

As macromarketers are concerned with the functioning and failure of marketing systems (e.g. Redmond 2013, 2018), so too the possible failure of alternative economies should be evaluated. Layton (2007) argued that "the effectiveness of a marketing system can be identified in the contribution of the assortments generated by the system to the quality of life of the relevant community" (227). Along these lines, this article will investigate the ways in which the assortments generated by alternative economies may not contribute positively to wellbeing. Failure of traditional marketing systems enhances the attraction of alternative systems, but they can still be vulnerable to failures.

While we wholeheartedly agree with the value that can be created through alternative economies, in recognizing the dark sides of alternative economies, stakeholders can better prepare in how to mitigate them, defend alternative economies to critics, and possibly even consider hybrid models that draw on the strengths of other types of economies. As such, our research question is: What are the unintended negatives consequences (i.e., dark sides) of alternative economies, founded on shared commitments, and how can the dark sides be mitigated in order for alternative economies to realize their goal of minimizing economic domination and exploitation?

More specifically, through a field study, we provide evidence from one alternative economy context about different types of dark sides that can develop as a result of shared commitments. The primary research site is Miss Silk's Farm (MSF), one of the most successful AFNs in Turkey, in which villagers are employed to grow and produce food sent to urban customers. MSF is an alternative economy because it is founded on shared commitments to minimize economic exploitation and aims to alleviate the subordinated position of local subjects (Campana, Chatzidakis, and Laamanen 2017).

We merge the findings obtained though the field study with the identified dark sides of alternative economies in the literature to offer an integrative framework that depicts micro, meso, and macro-level dark sides that can be produced by alternative economies. While much less prominent than the well-being outcomes of shared commitments, our data collection among the beneficiaries of MSF reveals how shared commitments can lead to disappointment, burnout, guilt, or isolation. Although there is missed opportunity in never pursuing shared commitments as a foundation for alternative economies, there is also danger in assuming alternative economy outcomes are always positive. Therefore, the aim is to present a framework of different types of dark sides that can emerge in alternative economies - a first step in being able to mitigate them.

\section{Definitional Issues}

Shared commitments derives from work by Day (2005) who advocates working from affinity, "nonuniversalizing, nonhierarchical, non-coercive relationships based on mutual aid and shared ethical commitments" (p. 9). The specific term of shared commitments was initially introduced by Campana, Chatzidakis, and Laamanen (2014). Later, Watson and Ekici (2017) developed an elaborated concept of shared commitment-"collective action toward a common goal for the long-term welfare of all" - as the foundation of alternative economies. This conceptualization is based on three dimensions of commitment identified by Gundlach, Achrol, and Mentzer (1995): behavioral, attitudinal, and temporal. In line with the former conceptualizations and the three dimensions of commitment, shared commitments have been defined as "a choice of a course of action in common with others... when actors take collective action toward a common goal for the long-term welfare of all" (Watson and Ekici 2017, p. 207).

We also want to clarify the shared commitment among whom. Shared commitments can be present or absent among any two actors or groups of actors in a network. Watson and Ekici (2017) explain that "shared commitments need to be dyadic in nature...or the commitment is not shared" (p. 213). In the case of MSF, we identified the primary actors as the owner, customers, and employees. For example, there could be shared commitment between one customer and one employee, or there could be shared commitments between the 
customers and employees overall. For shared commitments to be present, therefore, evidence should be found of at least two actors taking collective action toward a common goal for their mutual long-term welfare.

We elect to use the term dark sides to mean the unintended negative consequences of a social phenomenon. Positive or negative marketing system consequences have been dealt with as economic externalities or as social consequences (Mittelstaedt, Kilbourne, and Mittelstaedt 2006). If economic externalities are the uncalculated costs and benefits of exchange, a social consequence is an unanticipated effect on the parties in or out of the transaction (Nason 1989). Social consequences differ from the idea of externalities in their focus on the unanticipated, rather than the uncalculated (Mittelstaedt, Kilbourne, and Mittelstaedt 2006). Building on Haase, Becker, and Pick's (2018) point that "value creation processes can also have unintended consequences" (p. 61), we aim to present a conceptual framework of what we will call the dark sides of alternative economies. We will apply the practice of exploring the unintended social consequences of marketing systems to alternative economies.

Dark sides is often used in the literature to address the unintended negative consequences of terms generally esteemed in marketing systems, such as commitment, relationships, and trust. Related literatures on commitment, social capital, relationship marketing, and brand communities all address dark sides of networks, as they have been considered as the downsides of long-term relationships (Grayson and Ambler 1999) and trust (Numerato and Baglioni 2012). For example, while pointing to many benefits to commitment such as certainty, efficiency, and effectiveness, Dwyer, Schurr, and Oh (1987) also recognize that "There are bilateral sets of costs and benefits to relational exchange; a durable association is not necessarily desirable" (p. 25). Since marketing systems can also be thought of as relational networks (Arndt 1986), it is fitting to consider the dark sides that can exist in part because of the relational part of networks.

\section{Literature Review of Dark Sides of Alternative Economies and Shared Commitments}

In the next section we provide a background of the limited consideration of the dark sides of alternative economies in the macromarketing literature. We then provide a broader review from outside of macromarketing literature. Because shared commitments are the foundation of alternative economies (Watson and Ekici 2017), we consider related concepts such as trust, commitment, social capital, and organizational citizenship behaviors. We review the literature on the downsides that various stakeholders (such as customers, employees, and owner) of an organization may experience due to their involvement and commitment to one another. This review provides the background for an analytic framework of the specific dark sides of alternative economies.

\section{Dark Sides of Alterative Economies in Macromarketing Literature}

While alternative economies have gained greater attention in macromarketing literature, there is scant consideration given to the dark sides of alternative economies. A careful analysis of the dark sides evident in the articles in the $J M K$ Special Issue on alternative economies reveals that there are very few dark sides explicitly mentioned, and for the few there are, there is very little discussion about them. These dark sides can be broadly categorized as micro-level (an inside out perspective), meso-level, or macro-level (an outside in perspective) dark sides, in keeping with the levels of a marketing system established by Layton (2008). The micro-level dark sides are at the transactional and single organizational level. The meso-level dark sides come from the risks associated with alternative economies as systems. The macro-level dark sides are the negative social consequences (Mittelstaedt, Kilbourne, and Mittelstaedt 2006) for society resulting from alternative economies. At the end of this article we discuss how our primary data findings and theorization of dark sides sheds light on these other examples of alternative economies.

Micro-level dark sides are mentioned in some articles in the Special Issue, but noticeably absent from others. Scaraboto and Figueiredo (2017) identify a dark side of loss of reputation for people who cannot fulfill their obligation in the circulation of small chapels in Brazil. Benmecheddal, Gorge, and OzcalarToulouse (2017) hint at a micro-level dark side where freeriders use alternative currencies and never give back, taking advantage of the optimistic trust in another bartering actor. Gollnhofer and Schouten (2017) discuss the collaboration of activist consumers and retailers in the Foodsharing context to reduce food waste. Although not explicitly discussed, the alternative economy is vulnerable to dark sides if actors did try to take legal action against the retailers for sickness caused by the food (despite the legal disclaimer), to free-riders who take advantage of the non-monetary aspect of Foodsharing (not paying for food even if they are able), or retailers or consumers experiencing burnout or guilt through excessive effort to distribute the food or about not doing enough/ changing their level of involvement.

Through reviewing the existing literature, one may also identify meso-level dark sides of alternative economies. The meso level is concerned with the behavior of groups of firms or systems joined in a common enterprise (Layton 2008). It can be argued, for example, that a bartering system that springs up spontaneously may not prove enduring (Benmecheddal, Gorge, and Ozcalar-Toulouse 2017). Similarly, time banks may end up commodifying relations through their intent to revitalize social ties (Papaoikonomou and Valor 2017). In a relevant article outside of the Special Issue, Gollnhofer, Hellwig, and Morhart (2016) reveal the existence of contradictory fairness perceptions within an alternative economy, which can threaten broader support.

There are also some potential macro-level dark sides of alternative economies evident in the articles in the Special 
Issue. Gollnhofer and Schouten (2017) argue for the complementarity of the dominant social paradigm with sustainability, but acknowledge that movements such as Foodsharing may assuage a retailers' guilt over producing more than is environmentally preferable. Such complementary arrangements may delay more radical solutions in the long run, with a macro-level dark side of inoculating society against systemic change.

Benmecheddal, Gorge, and Ozcalar-Toulouse (2017) also discuss the challenge of networks extending beyond local communities. The research indicates that apart from legal status and political support, a bartering system that springs up spontaneously may prove ephemeral. The combining of traditional and alternative currencies and the evidence of the bartering and capitalist markets complementing each other expands the possibility for bridging between markets, without co-optation necessarily taking place.

Papaoikonomou and Valor (2017) hint at a macro-level dark side of the political logic of timebanking as limiting the diversity of users and services. Time banks may end up commodifying social relations through their intent to revitalize social ties. Another dark side may be the tension between the symbolic and functional sides of an alternative economy. Scaraboto and Figueiredo (2017) discuss how a hybrid regime of value that entangles multiple logics can lead to tensions between reputational, social, and religious regimes.

\section{Dark Sides of Alterative Economies Outside of Macromarketing Literature}

The review of several articles about alternative economies confirmed that they are vulnerable to many of the dark sides experienced by the beneficiaries in any organization where there are relationships and deep personal investment. However, we recognized that the nature of alternative economies founded on shared commitments may make them particularly vulnerable to certain dark sides. Reflection on the articles increased our intrigue to investigate the broader scope of different types of dark sides in alternative economies. As noted, an investigation that identifies potential dark sides is a step toward mitigating them and improving the well-being consequences of alternative economies. The following sections review the existing literature related to the dark sides of shared commitments, which are the foundation of alternative economies.

Dark sides of buyer-seller relationships. The marketing literature has long touted the advantages of buyer-seller relationships (e.g. Dwyer, Schurr, and Oh 1987) and commitment (e.g. Morgan and Hunt 1994). However, as the bright side has been advocated, the literature has also frequently warned of the dark sides of close relationships. Dwyer, Schurr, and Oh (1987) distinguish buyer-seller relationships from discrete exchanges. While pointing to many benefits to commitment such as certainty, efficiency, and effectiveness, they also recognize that "There are bilateral sets of costs and benefits to relational exchange; a durable association is not necessarily desirable" (p. 25). Moorman, Zaltman, and Deshpande (1992, p. 323) are more specific that "commitment and involvement bring about a familiarity that may breed boredom and a desire for new ideas." Grayson and Ambler (1999) show that long-term business relationships can go stale, lose effort and creativity, and decrease the ability to be objective, all of which could happen in alternative economies.

Commitment of all types is not always better for a service provider and customer. Fullerton $(2003,2005)$ argues that while affective commitment (liking and identification) leads to lower switching and higher advocacy intentions, continuance commitment (based on dependence and switching costs) can lessen these connections. Fournier, Dobscha, and Mick (1998) point out that customers can actually feel put at a disadvantage by their loyalty. New customers may get special introductory rates, while rates rise on long-time customers. Relationship marketing can alienate customers if it feels like a superficial attempt at friendship.

Dark sides of social capital. Dark sides of social capital are attempts to manipulate or misuse trust in order to achieve objectives that are at odds with the interest of others within a group, in a different group, or in society as a whole (Numerato and Baglioni 2012). Power can be intertwined with social capital in a way that brings about dark sides, such as preference for group members that are seen as more loyal. As such, alternative economies, which may operate on social capital and loyalty, may be subject to some of the same dark sides.

Villena, Revilla, and Choi (2011) point out that the value of social capital may begin to decay as the risks of social capital increase. Whereas social relationships can initially improve synergies, foster teamwork, and reduce undesirable behaviors, over time the supplier may become complacent, not acknowledge performance deterioration, and take advantage of reciprocity norms. The relational bonds may limit the transmittance of accurate feedback out of a wish to avoid unpleasant situations that could harm the maintenance of a friendship.

Social capital can be of both the bridging (between socially heterogeneous groups) and bonding (between socially homogeneous groups) variety (Putnam 2000).Van Deth and Zmerli (2010) call attention to the need for bridging social capital for social cohesion and collective action to take place. In the absence of bridging social capital, inward looking and isolated organizations can be prone to intolerance. An overemphasis on the local (without bridging social capital) can also "lead groups to become colloquial and blinkered to other acts of resistance around the world or even in their own region, leaving them exposed to defeat or even destruction by not building sufficient social alliances" (Amoore et al. 1997, p. 190).

Hickman and Ward (2007) call attention to the conflict that can be caused with people in the out-group. Looking at brand communities, they find that as brand loyalty grows, hostility toward others may breed stereotyping and trash talking. It is therefore important to consider not only the dark sides for those within the network, but the tension it may cause family members, friends, or others in the community or society who are not part of a particular alternative economy. 
Dark sides of organizational citizenship behaviors (OCBs). OCBs are behaviors that go beyond an employee's job description and include acts like helping others, taking on additional responsibilities, putting in extra hours, defending the organization, and speaking out about important organizational issues (Organ, Podsakoff, and MacKenzie 2005). Alternative economies may also expect extra effort in collective action and caring about the wellbeing of others. Although OCBs can make employees' jobs more enjoyable and rewarding (Organ, Podsakoff, and MacKenzie 2005), they may experience greater role ambiguity, role overload, job stress, and work-family conflict, particularly if they feel pressured to engage in such behaviors (Bolino et al. 2013).

Employees may experience "escalating citizenship" when engaging in OCBs becomes so normative that they must continually do more OCBs in order to meet expectations (Bolino and Turnley 2003). Escalating citizenship may contribute to competition and friction among workers who want to be seen as the most committed employees. This relates to the idea of job creep, which occurs when "employees feel ongoing pressure to do more than the requirements of their jobs" (Van Dyne and Ellis 2004, p. 181). The literature on work-family conflict suggests a dark side that greater investment in shared commitments for employees at work may have detrimental impacts on their family lives and therefore overall well-being (e.g. Halbesleben, Harvey, and Bolino 2009).

Other dark sides in literature. There are several other relevant dark sides in the literature, including burnout, disappointment, and free-riding. Burnout is generally defined as the degree to which a person experiences emotional exhaustion, depersonalization with co-workers, family, and clients, and a reduced sense of personal accomplishment, which can occur among individuals who work with people in some capacity (Maslach and Jackson 1981). Emotional exhaustion is generally considered as the first step in the burnout syndrome, followed by depersonalization, which leads to a feeling of decreased personal accomplishment (Leiter 1988). Burnout has been considered specifically among entrepreneurs (Shepherd et al. 2010), where there are high levels of stress along with factors such as loneliness and social isolation, immersion in business, people problems, and the constant need to achieve coupled with the drive and willingness to accept risks.

According to disappointment theory (Bell 1985; Loomes and Sugden 1986), individuals experience disappointment if the actual outcome is worse than the expected outcome. Disappointment is most likely when individuals seek a pleasurable outcome, when they feel it is just that they obtain their outcome, when the failure to obtain the outcome is a surprise, and when the failure is outside their personal control (van Dijk and Zeelenberg 2002). Ekici (2013) considers the dark sides of high trust relationships in a business context. Betrayal is a common dark-side consequence of trust between two parties. Setting high expectations, expecting a trusted partner to go the extra mile, being asked to do favors, and taking others for granted are among the dynamics that can lead to disappointment (Ekici 2013).
Free-riding is another dark side that can occur for members of an organization or alternative economy. Free-riding is when a member of a group obtains benefits from group membership but does not bear a proportional share of the costs of providing the benefits (Albanese and van Fleet 1985). Unlike OCBs, which can have a direct dark side for employees, there can be an indirect dark side for the hard-working employees who feel that their peers are free-riding. The decision to free-ride is based on a rational calculation of the net expected benefits of free riding versus contributing to the group's common interest (Stroebe and Frey 1982). Alternative economies are vulnerable to free-riding if some are working for the collective good and expecting others to do the same. In the next section we explain the methodology for exploring dark sides that have emerged as the result of shared commitments in a particular alternative economy.

\section{Methodology}

\section{Research Site}

An exploration of the dark sides of shared commitments was part of an ongoing study of an alternative food network (AFN) (Murdoch, Marsden, and Banks 2000; Watts, Ilbery, and Maye 2005; Jarosz 2008). The primary research site is Miss Silk's Farm (MSF), one of the most successful AFNs to recently emerge in Turkey against a backdrop of urbanization and the decline of local farming (Aydin 2010; Balaban 2012). We originally chose to study one predominant case in depth in order to observe the existence of shared commitments and generate learning about how they develop. The founder, Pinar Kaftancioglu, saw an opportunity to provide employment for the villagers by sending food to friends and others referred by her friends in Turkey's large cities. Clients place orders online, and then MSF fills boxes and ships them to customers' doorsteps using a commercial cargo company. Approximately 2,000 large boxes are sent out weekly. MSF employs about 100 people year-round, most of them women from the surrounding villages, with additional seasonal hires. MSF is an example of the multiplicity of economic forms: technically a for-profit company, but one that does not maximize profits or exploit its workers (Gibson-Graham 1996). Although enacted in a context influenced by capitalist norms and conventions, MSF is an alternative economy because it is not underpinned by profit motivations, but is founded on shared commitments to minimize economic domination and exploitation, exists in a local community to create localized development, and aims to alleviate the subordinated position of local subjects and improve human conditions (Campana, Chatzidakis, and Laamanen 2017).

\section{Data Collection and Analysis}

Our research into this alternative economy was multi-method, collecting data from semi-structured interviews, observations, and written, visual, and online documents. We recorded and transcribed over 35 hours of recorded interviews with the owner, consumers, MSF employees, and people in the producing community. The first author spent several days across two 
Table I. Informant Profiles.

\begin{tabular}{|c|c|c|c|c|c|c|c|}
\hline Name* & Category & Gender & Age (approx.) & Residence & Education & Area/Occupation & Years worked/ Customer of MSF \\
\hline Esra & Employee & $\mathrm{F}$ & 40 & Nazilli (small city) & Primary & Farmer & 4 \\
\hline Hande & Employee & $\mathrm{F}$ & 50 & Hamzalli (village) & Primary & Packer & I \\
\hline Damla & Employee & $\mathrm{F}$ & 35 & Nazilli (small city) & Primary & Cleaner & 6 \\
\hline Figen & Employee & $\mathrm{F}$ & 40 & Yaylapinar(village) & Primary & Baker & 3 \\
\hline Deren & Employee & $\mathrm{F}$ & 35 & Ocakli (village) & Primary & Dairy worker & 2 \\
\hline Merve & Employee & $\mathrm{F}$ & 30 & Sinekciler (village) & Primary & Kitchen & 2.5 \\
\hline Hatice & Employee & $\mathrm{F}$ & 40 & Nazilli (small city) & Secondary & Kitchen & 3 \\
\hline Suzan & Employee & $\mathrm{F}$ & 25 & Ocakli (village) & Bachelor's & Office & 7 \\
\hline Semra & Employee & $\mathrm{F}$ & 50 & Nazilli (small city) & Bachelor's & Office/ Manager & 3 \\
\hline Nihal & Employee & $\mathrm{F}$ & 25 & Nazilli (small city) & Secondary & Office & 1 \\
\hline Tarkan & Community & $M$ & 25 & Yaylapinar(village) & Primary & Waiter & N/A \\
\hline Veysel & Community & $M$ & 40 & Nazilli (small city) & Bachelor's & Business owner & N/A \\
\hline Rengin & Customer & $\mathrm{F}$ & 60 & Ankara (big city) & Graduate & Academic & 5 \\
\hline Aleyna & Customer & $\mathrm{F}$ & 40 & Ankara (big city) & Graduate & Academic & I \\
\hline Sarah & Customer & $\mathrm{F}$ & 35 & Ankara (big city) & Graduate & Housewife & 3 \\
\hline Yasin & Customer & $M$ & 40 & Ankara (big city) & Graduate & Academic & 3 \\
\hline Gizem & Customer & $\mathrm{F}$ & 45 & Ankara (big city) & Graduate & Academic & 1 \\
\hline Aslan & Customer & $M$ & 40 & Istanbul (big city) & Graduate & Business owner & 7 \\
\hline Emine & Customer & $\mathrm{F}$ & 35 & Istanbul (big city) & Graduate & Art curator & 4 \\
\hline Ceren & Customer & $\mathrm{F}$ & 40 & Istanbul (big city) & Graduate & Lawyer & 0.5 \\
\hline Ebru & Customer & $\mathrm{F}$ & 40 & Istanbul (big city) & Bachelor's & Engineer & 2 \\
\hline
\end{tabular}

*Names changed to protect privacy.

trips to MSF and in the surrounding community, observing employees and people in the community as they went about their lives and work. We also used snowballing to conduct indepth interviews with 12 current or former customers (see Table 1 for informant profiles).

Building on the already substantial amount of data collected about MSF, there were two primary thrusts for the exploration of dark sides. First, we read back through all of the data, coding for dark sides. We used a combination of open coding and axial coding to label, separate, compile, organize, and assign units of meaning to our data (Charmaz 1983; Miles and Huberman 1994). The first part of our analysis involved scanning all the data (520 pages of interview transcripts and 205 pages of documents) and searching for dominant and emerging themes related to dark sides. Our next stage was axial coding, where we explored relationships and patterns in the data around the various open-coded dark sides categories in order to create a data-driven conceptual structure to help understand possible dark sides of shared commitments in alternative economies.

Second, we conducted follow-up interviews with the different actors to understand more of the dark sides. In a third visit to the farm, the first author probed for dark sides of the farm for the owner and the employees. An additional step was to contact the dozen customers with whom interviews had been conducted earlier in the data collection process. Since 18 to 36 months had passed, many of them were no longer customers, and provided helpful insight into the overall view of the AFN. Although evidence of the dark sides was harder to collect, it helped balance the story from being a solely positive one and identify risks that could be mitigated.

\section{Findings}

We discovered five types of dark sides of shared commitment through the data collection and analysis of the alternative economy studied: Unreciprocated Commitments, Unfulfilled Goals, Investment Burnout, Adjustment Guilt, and Exclusivity Isolation. Each of these has a foundation from literature on dark sides of related phenomena, which was presented in the beginning of this paper. More importantly, we argue that each of these is a particular risk in alternative economies because of the expectation of shared commitments and better outcomes as a result. In the following sections, we offer highlights of the empirical evidence of when participants in the alternative food network experienced a particular dark side.

One of the findings from the analysis was a realization of dark sides at different levels among the micro-meso-macro spectrum (Layton 2008, 2010; Peterson 2016). In Table 2, we identify each of the dark sides, whether it was drawn from the primary data and/or literature on alternative economies, the 
Table 2. Integrative Framework of Dark Sides in Alternative Economies.

\begin{tabular}{|c|c|c|c|}
\hline Dark Side & Source & Level & Potential Threat To \\
\hline
\end{tabular}

Investment Burnout Field Work. difficulty in perceiving how the networks generates value for everyone in the group. (Scaraboto and Figueiredo 2017)

Adjustment Guilt

Field Work and Literature.

Loss of reputation for people who cannot fulfill their obligation in the circulation of small chapels in Brazil. (Scaraboto and Figueiredo 2017)

Free-riding

Bypassing Network

Literature.

Free-riders use alternative currencies and never give back, taking advantage of the optimistic trust in another bartering actor. (Benmecheddal, Gorge, and Ozcalar-Toulouse 2017)

Literature.

As a relationship between two members becomes stronger, they may go directly to each other, without registering/accounting for it with the timebank, compromising the activity levels of the network and not benefiting the collective. "Low marketness could limit activity and jeopardize the TB's longterm viability." (Papaoikonomou and Valor 2017, p. 176)

Ephemeral Literature.

Apart from legal status and political support, a bartering system that springs up spontaneously may prove ephemeral. (Benmecheddal, Gorge, and OzcalarToulouse 2017)

The "structuring effect of the norms and devices on the actors" (p. 168) may lead to ephemeral reality of many local exchange and trading systems. (Papaoikonomou and Valor 2017)

Exclusivity Isolation Field Work and Literature.

Exclusive local networks may lead to challenge of networks extending beyond local communities. (Benmecheddal, Gorge, and Ozcalar-Toulouse 2017)

Commodifying Relations

Regime Tensions

Literature.

Political logic of timebanking may limit the diversity of users and services. Time banks may end up commodifying social relations through their intent to revitalize social ties. (Papaoikonomou and Valor 2017)

Literature.

A hybrid regime of value that entangles multiple logics can lead to tensions between reputational, social, and religious regimes. (Scaraboto and Figueiredo 2017)

Change Inoculation Literature.

Movements such as Foodsharing may assuage a retailers' guilt over producing more than is environmentally preferable, delaying more radical solutions in the long run. (Gollnhofer and Schouten 2017)
Micro-Level Alternative Economies' Continuance

Micro-Level Alternative Economies' Continuance

Micro-Level Alternative Economies'

Meso-Level Continuance

Micro-Level Alternative Economies'

Meso-Level

Continuance

Meso-Level Alternative Economies' Continuance

Meso-Level Societal Well-being Macro-Level

Meso-Level Societal Well-being

Macro-Level

Meso-Level Societal Well-being Macro-Level

Macro-Level Societal Well-being main level at which it occurs, and whether it is more of a direct threat to alternative economies' continuance or societal wellbeing. We include Table 2 at the beginning of this section to orient the reader, but we will only present the findings about the five dark sides identified from the analysis of the data gathered from MSF. Later, we will explain the integration of the six other dark sides identified in the literature.

\section{Unreciprocated Commitments}

The first dark side of shared commitments we saw in MSF was the disappointment of unreciprocated commitments. This is related to the idea of betrayal (Ekici 2013). However, betrayal has a more personal and relational focus to it, that is part of but not the main focus of shared commitments. Shared commitments are oriented toward a common goal rather than relationship commitment (Morgan and Hunt 1994). Congruent values and goals is one of the three components of shared commitments (Watson and Ekici 2017). If something happens to challenge the similarity in values and goals, it can lead to the ill-being outcome of disappointment (or betrayal).

Customers of this alternative economy experienced unreciprocated commitments when there was a perceived violation of congruent values and goals. One of the most significant 
challenges to the shared commitments between the owner and customers of MSF came in 2014. Pinar ran for office on the local municipality board as a candidate for the ruling political party that many of her customers saw as detrimental to agriculture and women's rights. She also resigned from the party as soon as she won the seat, which was additionally controversial in the eyes of some of the customers. Rengin, in one of the later follow-up interviews after the election, explained how she cut off her interaction with Pinar.

In 2014, you remember the local elections. And you know that every week Pinar Hanim sends us a lot of information, she writes everything in detail, her plan, her ideas, etc. And her messages were the first that I read because of my respect and my pleasure of having the products at home from her. And one day I saw in a newspaper I guess her explanations about being a candidate from the party, and my first reaction that I felt was that I would like to hear this directly from her. I respect everybody's thoughts, decisions, actions, but if we did not have such a communication weekly, maybe I wouldn't care. I would like to know this, it shouldn't be a surprise for me. Whatever she wants she does, so I felt a bit like, you know I felt bad, as if somebody shares everything with you, but only hides this one thing from you. So I sent her an email saying that I respect your thoughts, beliefs, actions, but please take me out of your list. (Rengin)

In this quotation, we can see both the previous shared commitment, but then the unreciprocated commitment to expected congruent values and goals. Rengin alludes to the shared commitment she felt with the owner: her respect for the owner and reading her emails first every week. Rengin was the same customer who in an earlier interview said that Pinar was "like a friend that I have known for a very long time. I feel like that when I read her emails" (Rengin). Because of the closeness of their contact, Rengin was hurt when she was caught off guard by hearing this news from another source, as well as by the discrepancy it showed between their values. Pinar is esteemed by customers like Rengin as a fighter against the current government's agricultural policies and in favor of women's empowerment, but then took the seemingly contradictory action of running for office with that same ruling political party. As she explained further, Rengin said, "I mean I couldn't accept that becoming a member for a certain purpose and then resigning from it when you are at that point. [It was against] my ethical understanding of things" (Rengin). When I asked Rengin about the overall goal of MSF, she responded, "I had an idea in my mind, but with this decision I just felt confused about the goals." The shared commitment that Rengin felt, including their congruent values and collective action as demonstrated by frequency of contact around the goals of the farm, made her vulnerable to disappointment when she discovered apparent incongruence in their values.

The shared commitments between owner and customer can be a dark side in the sense that a customer who never felt shared commitments with the owner would not have been so disappointed by uninformed and incongruent actions. As Rengin herself said, "but if we did not have such a communication weekly, maybe I wouldn't care." It is because of the respect and the expectation of shared values that Pinar's actions came as such a disappointment. Participants in alternative economies may be even more vulnerable to the disappointment of unreciprocated commitments. Therefore, although shared commitments can lead to many well-being outcomes for customers (Watson and Ekici 2017), there is also a dark side of disappointment.

We also found evidence of employees and the owner experiencing the disappointment of unreciprocated commitments by their coworkers. Kevser shared her indignation with another employee who was complaining about the difficulty of her job. "Of course, not everyone is like us. Some people don't have the same mindset as us. Actually they can't have. Maybe with time could they be like us, I don't know." Kevser went on to emphasize the extraordinary effort they put in to make a variety of products from scratch to meet the customers' requests. She is disappointed by people in other departments who complain about the difficulty of the job, when she feels she is doing far more. She is frustrated by the free-riding of some employees, where there is a lack of consensus on everyone contributing equally to the benefits of being a part of MSF that they share (Albanese and Van Fleet 1985). A dark side of shared commitments can be the high standard it creates for other people to do the same level of work, as well as the frustration it causes the committed employees who do not see others taking the same collective action. The other employees considered by people like Kevser to be free-riders may experience the illbeing outcomes of the loss of esteem by other group members and a lower sense of self-worth (Stroebe and Frey 1982). The setting of high expectations and expecting a trusted partner to go the extra mile can lead to disappointment (Ekici 2013). Rengin and Kevser's experiences of unreciprocated congruency in values and goals and collective action by other actors exemplify the dark side of disappointment from unreciprocated commitments.

\section{Unfulfilled Goals}

Disappointment can also be a dark side when shared commitments do not lead to the expected outcomes. We discovered this in the customers of MSF, because they felt that they are taking collective action towards a particular goal, but were disappointed when they feel the goal is not being fulfilled. Unfulfilled goals is a particular risk for participants in alternative economies because they tend to have broader goals (the shared commitment dimension of congruent values and goals) than a transaction typical of a traditional market. Aleyna said in an earlier interview that she feels shared commitment through MSF is encouraging local women. She believes that Pinar "is really helping local women working over there, that is what I believe" (Aleyna). However, in a follow-up interview three years later, Aleyna shared how she became angry when she 
heard rumors that the employees of MSF were not benefiting from their involvement with the farm.

I heard that, maybe I don't know, maybe it was my fault because I did not have a chance to go there and see what is going on, because of the rumors I heard, I just stopped from buying there. Just the working conditions aren't good, especially for women, this and that. So I got affected from these things that I heard, then I stopped buying from that place...

First I was angry. I mean I am just buying because of this purpose, supporting ... of course I started thinking that rumors I heard were just not true. But the people I heard from are good friends of mine. (Aleyna)

Aleyna felt that the very reasons for which she was buying, the congruent values and goals and her shared concern for the future welfare of the employees, were being violated. (Having been to the farm and conducted extensive observations and interviews among the employees, we are confident these rumors are unsubstantiated. However, it is a fascinating example of the vulnerability of a network like MSF to rumors). The shared commitments Aleyna felt with the farm made her even more vulnerable to anger and feelings of disappointment when she heard rumors that the employees were not being treated well. According to disappointment theory (Bell 1985; Loomes and Sugden 1986), individuals experience disappointment if the actual outcome is worse than the expected outcome. Disappointment is likely for a customer like Aleyna who sought a pleasurable outcome, felt it unjust and out of her personal control that the outcome was not obtained, and was surprised by the failure (van Dijk and Zeelenberg 2002). The focus of unfulfilled goals is more about the disappointment of the unattained goal, which is the direction of shared commitments, than the letdown of shared commitments by another actor. In some situations even if everyone has honored their shared commitments, the goal may be unrealized, leading to disappointment.

The owner of MSF also shared the disappointment of unfulfilled goals. She is proud of what she has accomplished working together with the villagers, but is disappointed that she does not see the next generation of employees who will be able to continue on the traditional work of their mothers.

We are with the last working group. For example, right now we have people who make bazlama, etc. We have people who can make yukfa, hand baklava. This is the last generation. Right now these are 45-50 year old women. Their daughters are never going to do this kind of thing. There aren't going to be people who learn how to prepare yufka and baklava. They are disappearing. Because there is no one to be an apprentice, not a soul who wants to earn money doing this... I mean in the villages there aren't any young girls or whatever, who can make yufka and bazlama. I mean this work is done. We are working with the last generation. In 4-5 years the borek made at MSF will definitely have to go to automation. Outside of these strong older women we can't find any personnel to deal with this work by hand. For example, cutting pasta. At this point we have had to move on to cutting the dough by machine, with a machine from Italy. Currently we make the dough by hand, eggs, flour, etc. but from now on it will be with a machine. Because there is no one who wants to cut it by hand. I mean the hand workmanship, the handmade tastes are completely ending. We are working with the last generation. After, nothing. (Pinar)

Pinar expresses disappointment that the farm they have created based on the hard work of the traditional village women is dying. She is disappointed that the collective action she has taken with this generation of villagers is nearing its end. She values the hand workmanship done by these women and has found a market for them of customers who share the same values, but there is not anyone new taking up the work. Pinar is unable to find anyone to do the work, and it is changing how she thinks about the future of the farm and the goals she has been advocating. Pinar is currently so invested in the shared commitments toward the success of a network that produces traditional food and improves the lives of the women that to see the end of this achievement could bring great disappointment. A possible ill-being outcome could therefore be a reduced sense of personal accomplishment, decline in feelings of competence and successful career achievement (Maslach and Jackson 1981). Whereas unreciprocated commitments is a dark side based on the shared commitment between two actors, unfulfilled goals focuses on unrealized outcomes.

\section{Investment Burnout}

One dark side of shared commitment that we saw in a few employees was investment burnout from trying to invest in shared commitments. In the literature, when engaging in "organizational citizenship behaviors" becomes normative this has been referred to as "escalating citizenship" (Bolino and Turnley 2003). "Job creep" is another related term (Van Dyne and Ellis 2004). Participants in alternative economieswhether employees, customers, or an owner-are more likely to passionately invest themselves in a social mission they believe in and be at risk of burnout. While most of the employees of MSF enjoyed their jobs and affirmed how they did what they loved, there were a few employees who were wearied by the pace set by the more eager employees around them.

One of the employees interviewed said he finally finished work at midnight the night before. He said, "On average, it's like this 15 days out of 30 . I am here in the evenings. Because of this we're always here. It never changes. We spend more of our time here than at home" (Metin). Metin continues,

Our job really is great. The only problem is the hours problem. The start time is certain, but the ending time is not. There is no other problem. If the work hours were regular, super. I mean comfortable. But because it's not, what are you going to do? We accept it and necessarily keep coming... Because of the hours problem many people have left here. Those who can't accept it quit and leave.

Metin emphasized he loves his job other than the hours that have come to be expected. He says he stays in the job because 
he likes working in his village and not commuting back and forth to the city.

The ill-being in the life of the owner is increasing because of the strong opposition to the alternative way of agriculture she is advocating and a related dark side of investment burnout. Reflecting on the opposition she is experiencing in her efforts to advocate for healthier food, Pinar writes,

All of these things I have laughed about and moved past, but now the increasing threats are really making the people around me uneasy. It is tiring me out wondering if I should finally concede. Drawing up criminal complaints with my lawyer has become a routine part of my life ... as a result whether I like it or not I have even become a licensed weapon owner. I am uncomfortable. (Pinar, email, 13 February 2017)

Pinar is expressing fatigue over the strong reactions to her ongoing opposition of the industrialized food sector. Her burnout is not just from the physical threats, but the emotional strain of feeling she is swimming upstream with regard to the values surrounding food and agriculture. Pinar wrote at the end of this email, "My strength is your strength. Even if I wanted to say silent, I can't stop, you all know" (Pinar, email, 13 February 2017). In other words, her shared commitment to the goal is so great she cannot stop from speaking out, even at great cost to herself. Pinar reveals that she is struggling with burnout as a result of her efforts to lead an alternative economy.

\section{Adjustment Guilt}

Another dark side of shared commitments can be adjustment guilt. Alayna, a customer who decided to stop buying because of rumors about Pinar not treating the customers well, wrestled with feelings of guilt after she stopped. She describes at first feeling anger, then some guilt, and then assuaging her guilt by continuing her shared commitments in another network.

At the beginning, as I said, because I was angry, no [I didn't feel any guilt or shame]. But later on I thought that maybe it wasn't true, and then at that time maybe I felt a little bit guilty. At the beginning of course it was [hard to leave MSF]. On the one side, they are losing a customer, because [the employees] are earning money as I said. But since the things that I heard, when I first heard about it I was just so angry, but as time goes by I was just thinking, maybe it's not right, it's just a rumor, fighting with this in my mind. But other than that it was okay. There are other groups as well, so you can just easily buy in the same philosophy, there are some other people working as well. So I say to myself, I supported this group for two years, and now it is time to support those local people, living in Ankara, close to city. (Aleyna)

In this quotation, Aleyna reveals her struggle between anger and pangs of guilt over leaving. She initially felt anger over the disappointment of violated shared values (as discussed above), but later on she wrestled with whether leaving was the right thing to do. It was hard for her to leave because the farm was losing a customer that was helping the village women earn money. Her quote reveals that in order to decrease the guilt, it was vital to her that she invest in shared commitments to improve the welfare of local farmers in another context. The existence of shared commitments can lead to guilt for a participant in an alternative economy in a way that, for example, a customer would rarely feel who switches brands in a grocery store.

\section{Exclusivity Isolation}

Another dark side that was evident in some of the customer interviews was exclusivity isolation, when division from those outside the shared commitments is experienced if bonding is overemphasized at the expense of bridging social capital. Participants in an alternative economy are more likely to be bonded in shared commitments, and therefore more prone to isolation from people outside the network who do not share the same values. One of the customers shared her feeling that the owner of MSF can be overly aggressive:

$\begin{array}{ll}\text { Ebru: } & \text { When it comes to competing I find [Pinar] a bit } \\ & \text { aggressive. That's her style, as I said. } \\ \text { Interviewer: } & \text { In what way do you find her aggressive? } \\ \text { Ebru: } & \text { She would say, this is wrong, this is not right. Or } \\ & \text { you get the sense that only her way is the good } \\ & \text { way, any others are not good. }\end{array}$

While many customers appreciate Pinar's direct communication style and willingness to criticize existing agricultural practices, some customers like Ebru felt it went too far in "only her way is the good way." Another customer, Emine, feels that Pinar started with good intentions but that ambition has made her care more about only her own success. "There is an air of 'I am doing this job by myself.' This isn't right if you ask me. If you are doing this job, if you are an example, then you need to be a support to others. That is also a piece of this" (Emine). Pinar's dogmatic style helps the people within MSF bond together, but can obstruct bridging to other networks.

Whatever the case with MSF, it is vital that networks seeking to develop shared commitments stay aware of the need for balancing bonding and bridging. An overemphasis on bonding can "lead groups to become colloquial and blinkered to other acts of resistance around the world or even in their own region, leaving them exposed to defeat or even destruction by not building sufficient social alliances" (Amoore et al. 1997, p. 190). If networks can build bridges with others pursuing similar goals, they are more likely to achieve them.

The owner also experienced the dark side of exclusivity isolation. A special case of division from those outside the shared commitments is when the values and goals put the actors at odds with formidable opponents. The literature has pointed out that hostility toward others may breed stereotyping and trash talking and cause tension with others not part of the same brand community (Hickman and Ward 2007). However, if the shared commitments are a threat to another group of people or 
an entire industry, the degree of collective action and visibility can have a dark side, as Pinar describes from her experience:

While I have been speaking and telling veterinary department deans, doctor's associations, chamber of food engineers, agricultural associations; I felt very alone as everyone preferred that I would stay silent on what needs to be said about food. The outcomes of the impractical efforts of these group to silence me has from time to time made me, but most of the time my family nervous. You are in the village, you are a woman ... Leaving aside the lawsuits that have been filed by the food cartels and the organizations that exploit the organic product sector... I am constantly battling with them. (Pinar, email, 13 February 2017)

Pinar shares with her supporters the growing threats she feels directed at her. She shares that many different associations that are a part of the established food sector and medical professions are trying to silence her. There have been direct threats at her and her family. She feels defamed by her adversaries. Pinar enjoys the bonding with a strong network of employees and customers who have shared commitments, but experiences the dark side of isolation from those outside of shared commitments.

We have presented our findings of five dark sides based on our primary data analysis. The next section will discuss how these were integrated with the other six dark sides identified in the literature (also shown in Table 2), as well as provide more textured discussion of the three-level classification of dark sides.

\section{Discussion}

The integrative framework (depicted in Table 2 at the beginning of the previous section) is an amalgamation of our primary research findings and the dark sides identified in the related research presented in the literature review. We will discuss the integrated framework based on the relationships between different levels of dark sides in light of the macromarketing literature about alternative economies, which leads to the three level classifications of dark sides, and from the perspective of market system failure. Finally, we will discuss possible remedies to mitigate the dark sides of alternative economies.

\section{Integrative Framework of Dark Sides of Shared Commitments and Alternative Economies}

The integrated framework was developed based on the comparison of the dark sides uncovered through the primary data collection and analysis of MSF with the extant macromarketing literature on alternative economies, which was introduced at the start of this paper. We identified overlapping dark sides and played with different classifications to reach the final framework.

Table 2 identifies the dark sides of alternative economies based on varying levels. Following in the mode of Layton (2008), the table distinguishes micro, meso, and macro-levels of analysis. Alternative economies are an example of a market system at the meso or intermediate level (Layton 2008). Alternative economies are therefore at the interface of micro and macro-level perspectives, which is of particular interest to the macromarketer (Layton 2008). On the micro side, shared commitments are the micro-level foundation of alternative economies (Watson and Ekici 2017). They are micro because at the most basic they are developed in the dyadic interaction of two actors. On the macro side, alternative economies aim for system change - to minimize economic domination and exploitation at the societal level (Campana, Chatzidakis, and Laamanen 2017).

At the interface between micro and macro perspectives, alternative economies can be evaluated from the "inside out" and "outside in" points of view (Layton 2008). Investigating alternative economies from the "inside out" necessitates the study of the dark sides that result from shared commitments. The "outside in" encourages looking critically at alternative economies through the broader environmental, social, and political effects.

Taking the "inside out" perspective into account, one may argue that the micro-level dark sides resulting from shared commitments can lead to the failure of the alternative economy. For example, as will be explained in detail in the next section, if enough actors continue to experience unfulfilled goals the alternative economy will not be considered worthwhile and eventually fizzle. In the case of failure, alternative economies may also prove to be more ephemeral than traditional economies (Papaoikonomou and Valor 2017), in part because they lack the institutional support and longestablished consumer habits. In Table 2, there is a column that identifies the threat of the dark sides. The first seven dark sides, at the micro and meso-levels, are a direct threat to the continuance of the alternative economy. Efforts to mitigate these dark sides can help the survival of the alternative economy.

If the alternative economy survives, it has the chance to continue to achieve the societal benefits for which participants are laboring. However, even if an alternative economy survives and continues, it can result in negative social consequences (i.e., dark sides) for society, as shown from our primary research findings and other examples about alternatives economies from the macromarketing literature. The last four dark sides, the ones which include a macro-level dimension, are a direct threat to societal well-being (shown at the bottom of Table 2). Of course, the dark sides that are a threat to the continuance of the alternative economy will eventually also be a threat to societal well-being. In this distinction, our synthesis of the data shows that some of the dark sides undermine the alternative economies themselves, whereas alternative economies can also produce dark sides that jeopardize their very goal of improving societal well-being. For example, as will be explained later in detail, the very success of an alternative economy can have the unintended consequence of curbing consumers' energy for greater systemic changes. Dark sides are another way of describing externalities and internalities. Redmond (2018) suggests that negative 
internalities resulting in unanticipated costs may be more harmful to marketing systems than to traditional transactional markets. Redmond also points out how "Over-reliance on other system members may produce several modes of negative internalities" and "opportunistic behavior or fraud by system members can harm others in the system" (p. 417), both of which we substantiate in our study.

As such, our analysis informs the ongoing and recent macromarketing discussion about the functioning and possible failure of marketing systems. Redmond (2018), for example, clarifies the distinction between market failure- external performance, usually tied to consumer welfare - and market decline - internal performance related to growth and sales. Our analysis has shown that there can be dark sides whether an alternative economy declines or thrives. Alternative economies likewise need to be in the conversation about how they are functioning and leading to positive or negatives internalities and externalities, or what is known as social consequences (Mittelstaedt, Kilbourne, and Mittelstaedt 2006).

\section{The Three Levels of Dark Sides}

Table 2 identified the dark sides of alternative economies, which, as we noted, were derived from blending our case analysis and relevant dark side literature. The list of dark sides is also oriented around micro, meso, and macro levels of analysis. The dark sides are therefore in a descending order from the more micro-level to the more macro-level dark sides. The micro-level dark sides come from the risks associated with violations of shared commitments between actors-namely collective action, congruent values and goals, and concern for the future welfare of other actors (Watson and Ekici 2017). These micro-level dark sides are related to the dark sides of buyer-seller relationships and OCBs identified in the literature review, which are accordingly at the transactional and single organizational level. The meso-level dark sides come from the risks associated with alternative economies as systems. The macro-level dark sides deal with the negative social consequences (i.e., dark sides) for society resulting from alternative economies.

The micro-level dark sides identified through our analysis of MSF include unreciprocated commitments, unfulfilled goals, and adjustment guilt. Some of the micro-level dark sides are evident in previous work on alternative economies, but noticeably absent from others. Scaraboto and Figueiredo (2017) identify a dark side of loss of reputation for people who cannot fulfill their obligation in the circulation of small chapels in Brazil, which corresponds to the adjustment guilt found in MSF. The stealing and images breaking due to careless handling of a small chapel are examples of possible unreciprocated commitments. Scaraboto and Figueiredo (2017)'s research also reveals how although people have good will, the system is not consistently strong enough to maintain and distribute created value in the alternative economy. Participants' difficulty in perceiving how the networks generate value for everyone in the group is an example of unfulfilled goals.
From reviewing the existing macromarketing literature we also identified a dark side of people bypassing network when they form shared commitments through the help of the alternative economy, but then do not remain connected to the network for future exchanges, therefore not benefiting everyone (Papaoikonomou and Valor 2017). Free-riding (e.g. Benmecheddal, Gorge, and Ozcalar-Toulouse 2017) is another dark side because people can more easily take advantage of the shared commitments that undergird alternative economies. The existence of dark sides does not preclude the well-being outcomes of hybrid value regimes in alternative economies, but corroborates our findings that both exist simultaneously.

The meso level is about the behavior of groups of firms or systems joined in a common enterprise, including the study of markets, supply chains, and channels (Layton 2008). There are several meso-level dark sides identified through the primary research and literature review of other case studies of alternative economies. Apart from legal status and political support, a bartering system that springs up spontaneously may prove ephemeral (Benmecheddal, Gorge, and Ozcalar-Toulouse 2017). The "structuring effect of the norms and devices on the actors" (p. 168) may lead to ephemeral reality of many local exchange and trading systems (Papaoikonomou and Valor 2017). Exclusive local networks may lead to exclusivity isolation and the challenge of networks extending beyond local communities (Benmecheddal, Gorge, and Ozcalar-Toulouse 2017), which is in line with what we found in the MSF case. Political logic of timebanking may limit the diversity of users and services. Time banks may end up commodifying relations through their intent to revitalize social ties (Papaoikonomou and Valor 2017).

Most of these meso-level dark sides can also result in unintended negative consequences at the macro-level. The effectiveness of a marketing system should be evaluated in the contribution of the assortments generated by the system to the quality of life of the community (Layton 2007). Such an evaluation calls for investigations of both benefits and dark sides of both mainstream and alternative economies. As benefits, alternative economies can bring about solidarity with others and facilitate collective action for societal exchange. However, on the dark side, exclusivity isolation, which we saw in the case of MSF, can result in greater fragmentation in society and inhibit collective action toward societal goals. A hybrid regime of value that entangles multiple logics can lead to regime tensions between reputational, social, and religious regimes (Scaraboto and Figueiredo 2017). Opposing institutional logics about redistribute justice contested within an alternative economy can have macro-level implications of regime tensions within society (Gollnhofer, Hellwig, and Morhart 2016). Change inoculation is a macro-level dark side. Movements such as Foodsharing may assuage a retailers' guilt over producing more than is environmentally preferable, delaying more radical solutions in the long run (Gollnhofer and Schouten 2017). Our primary research and review of extant literature has shown the existence of dark sides of alternative economies at all system levels. 


\section{Contributions to Macromarketing Literature}

Macromarketers have been advised to provide a better understanding of how marketing systems work and don't work for people in societies (Layton 2007; Peterson 2016). Alternative economies are important alternatives to the predominant capitalist system. Shared commitments is one of the mechanisms that enables alternative economies to function. However, this article has shown ways in which alternative economies do not always work well for the people who participate in them or who are outside of them. It cannot be taken for granted that alternative economies will lead to general societal flourishing. The reason we point out the dark sides is so that we can achieve a greater system functioning.

In his research on marketing systems, Layton (2007) refers to market and/or system failures and externalities (Table 1, p. 238). Our research goes into more details about the system failures or dark sides that can occur. In particular, building from shared commitments as the foundation of alternative economies (Campana, Chatzidakis, and Laamanen 2014), we have identified several relational dark sides that can result from alternative economies. Layton (2007) includes relationships in the components and attributes sections of the table on researching marketing systems, but not in the outcomes. We add to the conceptualization of systems failure with identifying relational dark sides such as commodifying relationships, exclusivity isolation, and adjustment guilt. Perhaps in alternative economies, where shared commitments and trust are so foundational, the relational dark sides are a greater risk. While the relational aspect of alternative economies where "actors in alternative economies pursue value creation in a way that expresses relationships between human beings" (Haase, Becker, and Pick 2018 , p. 57) is typically seen positively, we found evidence of potential negative outcomes.

As such, since marketing systems can be thought of as relational networks (Arndt 1986), we contribute to the literature on systems by identifying the dark sides and not just the positive sides of relational networks. Arndt (1986) stated that "most transactions are effected not through ad hoc market encounters but in the context of stable relationships within networks" (p. 125). Unfortunately, relationships do not always remain stable, leaving alternative economies and marketing systems vulnerable to the dark sides identified in this article. A desire for shared commitments that go beyond ad hoc market encounters draws people toward alternative economies, but does not insulate them from dark sides.

Layton (2010) provided an excellent taxonomy of how marketing systems that function well can greatly contribute to well-being. Peterson's (2016) modification of Layton's figure to the "Macro Cross" concept highlights the underresearched marketing systems, of which alternative economies are a part. In many cases, alternative economies are Emergent on the vertical axis of the degree of planning in the marketing system. With regard to the horizontal axis, alternative economies can span micro, meso, and macro levels, as we have discussed in this article. Alternative economies are also akin to intermediaries, farmers markets, open source, and the informal sector.

This study provides a detailed look at how certain systems within the Macro Cross may create unintended negative social consequences (i.e., dark sides), which we believe could offer a theory-based explanation for dark sides of the Macro Cross systems. As various stakeholders continue to co-create value, they do well to guard against the dark sides that can result from shared commitments.

The MSF case also corroborates some of the cautions offered by Redmond (2013) in his marketing systems review of the US housing crisis. Alternative networks like MSF, as with the housing market, can bypass traditional quality assurance providers in a way that opens the system to additional risk. The rapid rise of MSF and the demand of affluent customers to buy products from unproven producers opens the network up to dark sides. The customers of MSF and other alternative economies are influenced by the assumption and ideologies (Redmond 2013) put forth by owners and managers of these networks, but a lack of scrutiny can make people susceptible to abuse of trust.

\section{Recommendations for Solutions to Mitigate Dark Sides}

We have argued for the importance of recognizing and attempting to mitigate the dark sides of alternative economies. To this end, we offer recommendations to guard against the vulnerabilities at the micro and macro-levels. At the micro-level, we consider what can be done in individual alternative economies to reduce burnout or free-riding. According to our synthesis of the data, those in alternative economies need to be cautious about "escalating citizenship" (Bolino and Turnley 2003). When organizational citizenship behaviors (Organ, Podsakoff, and MacKenzie 2005; Bolino et al. 2013) place too much strain on participants in an alternative economy, burnout will follow. Founders/administrators of alternative economies need to set the example in having boundaries on their working hours to have time to rest and recharge rather than constantly be with people. Although the enthusiasm around shared commitments is what distinguishes alternative economies, moderation is required to avoid burnout. Otherwise, participants may find refuge in the more sterile but less emotionally taxing predominant economy.

In order to reduce free-riding (Albanese and van Fleet 1985), the importance of shared commitments can be better communicated and a standard of accountability utilized. Organizers of alternative economies should evaluate whether someone is not contributing out of genuine need or out of a lack of shared commitment. If not taken seriously, the dark side of the unreciprocated commitments can eventually erode the viability of an alternative economy.

We also recommend that alternative economies not center on the personality of one charismatic leader. It is natural for any organization or network to begin through charismatic leadership, and indeed alternative economies can develop similarly. However, our analysis suggests that alternative economies are 
more at risk of dark sides when too much of the focus is on a single leader. One of the criticisms of MSF is an arrogant founder who advocates her way as the only and best way. In addition to burnout for the leader, it can lead to disillusionment if the person is even accused of being self-serving, which often follows with power and notoriety. A dominant leader tends toward an amoral and crisis-ridden rather than an ethical and harmonious environment as alternative economies aspire to be (Campana, Chatzidakis, and Laamanen 2017, Table 1, adapted from Gibson-Graham 2006, p. 126). A network with shared ownership of and work toward the vision mitigates some of the dark sides of alternative economies.

At the macro-level, we recommend the importance of networks of alternative economies. Interaction with participants in other alternative economies will help minimize exclusivity isolation. In other words, bridging social capital facilitates ideas and participants flowing more freely. There may still be tensions between different regimes, but forums that facilitate communication encourages the finding of common goals around which networks can work together. Leaders of alternative networks as well as government agencies can sponsor events where ideas and policies are discussed. Exposure to radical ideas presented at such events can also shield against change inoculation. All alternative economies should be affirmed as part of a movement toward change but not be viewed as an end in themselves.

The risks, for example of commodifying relations, should be acknowledged. The alternative economies should accept when people move away from the platforms, while gently encouraging them of the value of remaining part of a network that will be benefit more people. Actors interested in the advancement of alternative economies would do well to see this as a multifaceted movement rather than individual tightly managed organizations, as for-profit companies typically aim to be. If the overall shared commitments amongst alternative economies are growing, there will be a bigger pie from which the alternative economies will be able to share.

Interaction amongst the actors in alternative economies can also mitigate the dark sides when alternative economies fail. Even if one alternative economy is ephemeral and disappears, the actors may be able to continue to demonstrate their shared commitments through another network. While the disappointment of actors not living up to their shared commitments could lead to disillusionment, it will help if actors are aware of other functioning alternative economies where shared commitments are still being maintained.

Tighter networks of alternative economies can also serve the purpose of providing a type of accountability for the leaders of such networks. Leaders may be dissuaded from discouragement in their efforts and from unethical actions when networked with leaders in other alternative economies. As for public policy, the government may provide some oversight for alternative economies. Although members and other leaders of other alternative economies, as well as the media, may be able to provide some accountability, there may be a place for the government checking on accounting practices, the fair treatment of employees, and quality. Regulatory failure can enable market failure (Redmond 2009). Interestingly, alternative economies such as AFNs, often times arise out of regulatory failure and the lack of confidence consumers have in regulations to protect their (health) interests. But a lack of regulation can open consumers to other health or trust risks, as discussed in this article. Such governance would be with the aim to prevent people's trust being taken advantage of and the ensuing disillusionment that could further damage the efforts of alternative economies.

\section{Conclusion}

Alternative economies can significantly contribute to societal flourishing (Campana, Chatzidakis, and Laamanen 2017). However, the dark sides of alternative economies should also be considered. We reviewed the literature on the drawbacks of close relationships and commitments. We presented qualitative data of when the beneficiaries of MSF experienced several dark sides within this alternative economy. While much less prominent than the well-being outcomes of shared commitments, the dark sides provide a cautionary word of how shared commitments can lead to disappointment, burnout, guilt, or isolation.

Comparing with the dark sides gleaned from the other studies on alternative economies, we developed a framework (Table 2) for comprehensively thinking about dark sides in alternative economies. The dark sides can be along a spectrum from the micro level (as a result of shared commitments) to the macro level. We offered recommendations to guard against the vulnerabilities of alternative economies for their continuing growth and impact, as well as discussed the implications for research on marketing systems failure.

Future studies could offer additional empirical evidence from alternative economies in other contexts in order to explore the generalizability of the framework offered in this paper. Future research can also classify approaches to mitigate the dark sides of alternative economies and evaluate their effectiveness. As the body of work on alternative economies continues to grow, so too should the analysis of the dark sides of the phenomenon in order to maximize societal benefit.

\section{Acknowledgments}

The authors thank editor Mark Peterson and his wife Cindy for their professional and personal investment in the macromarketing community. We also thank the associate editor and three anonymous reviewers for their support and constructive comments. We dedicate this paper to Banner Davut Watson (May 6, 2011- March 17, 2018).

\section{Declaration of Conflicting Interests}

The author(s) declared no potential conflicts of interest with respect to the research, authorship, and/or publication of this article.

\section{Funding}

The author(s) received no financial support for the research, authorship, and/or publication of this article. 


\section{ORCID iD}

Forrest Watson (D) https://orcid.org/0000-0002-8820-1434

\section{References}

Albanese, Robert and David D. Van Fleet (1985), "Rational Behavior in Groups: The Free-riding Tendency," Academy of Management Review, 10 (2), 244-55.

Amoore, Louise, Richard Dodgson, Barry K. Gills, Paul Langley, Don Marshall, and Iain Watson (1997), “Overturning 'Globalisation': Resisting the Teleological, Reclaiming the 'Political'," New Political Economy, 2 (1), 179-95.

Arndt, Johan (1986), "Shared Symbols, Meanings, and Ways of Life in Interorganizational Networks," in Marketing Management Technology as a Social Process, G. Fisk, ed. New York: Praeger Publisher, 121-38.

Aydin, Zulkuf (2010), "Neo-Liberal Transformation of Turkish Agriculture," Journal of Agrarian Change, 10 (2), 149-87.

Balaban, Osman (2012), "The Negative Effect of Construction Boom on Urban Planning and Environment in Turkey: Unraveling the Role of the Public Sector," Habitat International, 36 (1), 26-35.

Bell, David E. (1985), "Disappointment in Decision Making Under Uncertainty," Operations Research, 33 (1), 1-27.

Benmecheddal, Ahmed, Hélène Gorge, and Nil Özçağlar-Toulouse (2017), "Rethinking Alternative Markets in the Context of Economic Crisis and Austerity in Greece," Journal of Macromarketing, 37 (2), 193-205.

Bolino, Mark C. and William H. Turnley (2003), "Going the Extra Mile: Cultivating and Managing Employee Citizenship Behavior," Academy of Management Perspectives, 17 (3), 60-71.

Bolino, Mark C., Anthony C. Klotz, William H. Turnley, and Jaron Harvey (2013), "Exploring the Dark Side of Organizational Citizenship Behavior," Journal of Organizational Behavior, 34 (4), 542-59.

Campana, Mario, Andreas Chatzidakis, and Mikko Laamanen (2014), "Special Issue on Alternative Economies, 2017," Journal of Macromarketing, 34 (3), 408-09.

Campana, Mario, Andreas Chatzidakis, and Mikko Laamanen (2017), "Introduction to the Special Issue: A Macromarketing Perspective on Alternative Economies," Journal of Macromarketing, 37 (2), 125-30

Charmaz, Kathy (1983), “The Grounded Theory Method: An Explanation and Interpretation," in Contemporary Field Research: A Collection of Readings, Robert M. Emerson, ed. Boston, MA: Little Brown, 109-26.

Day, Richard J. (2005), Gramsci Is Dead: Anarchist Currents in the Newest Social Movements. London: Pluto Press.

Dwyer, F. Robert, Paul H. Schurr, and Oh Sejo (1987), "Developing Buyer-Seller Relationships," Journal of Marketing, 51 (April), $11-27$.

Ekici, Ahmet (2013), "Temporal Dynamics of Trust in Ongoing Interorganizational Relationships," Industrial Marketing Management, 42 (6), 932-49.

Ekici, Ahmet, M. Joseph Sirgy, Dong-Jin Lee, B. Yu Grace, and Michael Bosnjak (2018), "The Effects of Shopping Well-Being and Shopping Ill-Being on Consumer Life Satisfaction," Applied Research in Quality of Life, 13 (2), 333-53.
Fournier, Susan, Susan Dobscha, and David Glen Mick (1998), "The Premature Death of Relationship Marketing," Harvard Business Review, 76 (1), 42-51.

Fullerton, Gordon (2003), "When Does Commitment Lead to Loyalty?" Journal of Service Research, 5 (4), 333-44.

Fullerton, Gordon (2005), "How Commitment Both Enables and Undermines Marketing Relationships," European Journal of Marketing, 39 (11/12), 1372-88.

Gibson-Graham, Julie Katherine (1996), The End of Capitalism (as We Knew It): A Feminist Critique of Political Economy. Minneapolis, MN: University of Minnesota Press.

Gibson-Graham, Julie Katherine (2006), A Postcapitalist Politics. Minneapolis, MN: University of Minnesota Press.

Gollnhofer, Johanna F., Katharina Hellwig, and Felicitas Morhart (2016), "Fair is Good, But What is Fair? Negotiations of Distributive Justice in an Emerging Nonmonetary Sharing Model," Journal of the Association for Consumer Research, 1 (2), 226-45.

Gollnhofer, Johanna F. and John W. Schouten (2017), "Complementing the Dominant Social Paradigm with Sustainability," Journal of Macromarketing, 37 (2), 143-52.

Gundlach, Gregory T., S. Achrol Ravi, and T. Mentzer John (1995), "The Structure of Commitment in Exchange," Journal of Marketing, 59 (1), 78-92.

Grayson, Kent and Tim Ambler (1999), "The Dark Side of Long-term Relationships in Marketing Services," Journal of Marketing Research, 36 (February), 132-41.

Haase, Michaela, Ingrid Becker, and Doreén Pick (2018), “Alternative Economies as Marketing Systems? The Role of Value Creation and the Criticism of Economic Growth," Journal of Macromarketing, 38 (1), 57-72.

Halbesleben, Jonathon, Jaron Harvey, and Mark C. Bolino (2009), "Too engaged? A Conservation of Resources View of the Relationship Between Work Engagement and Work Interference with Family," Journal of Applied Psychology, 94 (6), 1452.

Hickman, Thomas and James Ward (2007), "The Dark Side of Brand Community: Inter-group Stereotyping, Trash Talk, and Schadenfreude," in NA - Advances in Consumer Research, Vol. 34, Gavan Fitzsimons and Vicki Morwitz, eds. Duluth, MN: Association for Consumer Research, 314-19.

Jarosz, Lucy (2008), "The City in the Country: Growing Alternative Food Networks in Metropolitan Areas," Journal of Rural Studies, 24 (3), 231-44.

Laczniak, Gene R. and Nicholas J. C. Santos (2011), "The Integrative Justice Model for Marketing to the Poor: An Extension of SD Logic to Distributive Justice and Macromarketing," Journal of Macromarketing, 31 (2), 135-47.

Layton, Roger A. (2007), "Marketing Systems-A Core Macromarketing Concept," Journal of Macromarketing, 27 (3), 227-42.

Layton, Roger A. (2008), "The Search for a Dominant Logic: A Macromarketing Perspective," Journal of Macromarketing, 28 (3), 215-27.

Layton, Roger A. (2009), “On Economic Growth, Marketing Systems, and the Quality of Life," Journal of Macromarketing, 29 (4), 349-62.

Layton, Roger A. (2010), "Marketing Systems, Macromarketing and the Quality of Life," in The SAGE Handbook of Marketing Theory, 
Pauline Maclaran, Michael Saren, Barbara Stern, and Mark Tadajewski, eds. London, UK: Sage, 415-42.

Leiter, Michael P. (1988), "Burnout as a Function of Communication Patterns: A Study of a Multidisciplinary Mental Health Team," Group \& Organization Studies, 13 (1), 111-28.

Lloveras, Javier and Lee Quinn (2017), "Growth and Its Discontents: Paving the Way for a More Productive Engagement with Alternative Economic Practices," Journal of Macromarketing, 37 (2), 131-42.

Loomes, Graham and Robert Sugden (1986), "Disappointment and Dynamic Consistency in Choice Under Uncertainty," The Review of Economic Studies, 53 (2), 271-82.

Maslach, Christina and Susan E. Jackson (1981), "The Measurement of Experienced Burnout," Journal of Organizational Behavior, 2 (2), 99-113.

Miles, Matthew B. and A. Michael Huberman (1994), Qualitative Data Analysis: An Expanded Sourcebook. Thousands Oaks, CA: Sage.

Mittelstaedt, John D., William E. Kilbourne, and Robert A. Mittelstaedt (2006), "Macromarketing as Agorology: Macromarketing Theory and the Study of the Agora," Journal of Macromarketing, 26 (2), 131-42.

Mittelstaedt, John D., Clifford J. Shultz, William E. Kilbourne, and Mark Peterson (2014), "Sustainability as Megatrend: Two Schools of Macromarketing Thought," Journal of Macromarketing, 34 (3), 253-64.

Moorman, Christine, Gerald Zaltman, and Rohit Deshpande (1992), "Relationships Between Providers and Users of Market Research: The Dynamics of Trust," Journal of Marketing Research, 29 (3), 314-28.

Morgan, Robert M. and Shelby D. Hunt (1994), "The CommitmentTrust Theory of Relationship Marketing," The Journal of Marketing, 58 (July), 20-38.

Murdoch, Jonathan, Terry Marsden, and Banks Jo (2000), "Quality, Nature, and Embeddedness: Some Theoretical Considerations in the Context of the Food Sector," Economic Geography, 76 (2), 107-25.

Nason, Roger W. (1989), "The Social Consequences of Marketing: Macromarketing and Public Policy," Journal of Public Policy \& Marketing, 8 (1989), 242-51.

Numerato, Dino and Simone Baglioni (2012), "The Dark Side of Social Capital: An Ethnography of Sport Governance," International Review for the Sociology of Sport, 47 (5), 594-611.

Organ, Dennis W., Philip M. Podsakoff, and Scott B. MacKenzie (2005), Organizational Citizenship Behavior: Its Nature, Antecedents, and Consequences. Thousand Oaks, CA: Sage.

Papaoikonomou, Eleni and Carmen Valor (2017), "The Institutionalization of Alternative Economies: The Processes of Objectification in Time Banks," Journal of Macromarketing, 37 (2), 167-79.

Peterson, Mark (2016), “Think Macro!,” Journal of Macromarketing, 36 (2), 124-25.

Putnam, Robert D. (2000), "Bowling Alone: America's Declining Social Capital," in Culture and Politics, L. Crothers and C. Lockhart, eds. New York: Palgrave Macmillan, 223-34.

Redmond, William (2009), “A Political Economy of Regulatory Failure in US Packaged Food Markets," Journal of Macromarketing, 29 (2), 135-44.
Redmond, William (2013), "A Marketing Systems View of the U S Housing Crisis," Journal of Macromarketing, 33 (2), 117-27.

Redmond, William (2018), "Marketing Systems and Market Failure: A Macromarketing Appraisal," Journal of Macromarketing, 38 (4), 415-24.

Scaraboto, Daiane and Bernardo Figueiredo (2017), "Holy Mary Goes 'Round: Using Object Circulation to Promote Hybrid Value Regimes in Alternative Economies," Journal of Macromarketing, 37 (2), 180-92.

Shepherd, C. David, Gaia Marchisio, Sussie C. Morrish, Jonathan H. Deacon, and Morgan P. Miles (2010), "Entrepreneurial Burnout: Exploring Antecedents, Dimensions and Outcomes," Journal of Research in Marketing and Entrepreneurship, 12 (1), 71-79.

Stroebe, Wolfgang and Bruno S. Frey (1982), "Self-interest and Collective Action: The Economics and Psychology of Public Goods," British Journal of Social Psychology, 21 (2), 121-37.

Deth, Van, W. Jan, and Sonja Zmerli (2010), "Introduction: Civicness, Equality, and Democracy - A "Dark Side" of Social Capital?," The American Behavioral Scientist, 53 (5), 631-39.

Van Dijk, W. W. and M. Zeelenberg (2002), "Investigating the Appraisal Patterns of Regret and Disappointment," Motivation and Emotion, 26 (4), 321-31.

Van Dyne, Linn and Jennifer Butler Ellis (2004), "Job Creep: A Reactance Theory Perspective on Organizational Citizenship Behavior as Over-Fulfillment of Obligations," in The Employment Relationship: Examining Psychological and Contextual Perspectives, J. Coyle Shapiro, L. M. Shore, S. Taylor, and L. E. Tetrick, eds. Oxford, UK: Oxford University Press, 181-205.

Villena, Verónica H., Elena Revilla, and Thomas Y. Choi (2011), "The Dark Side of Buyer-Supplier Relationships: A Social Capital Perspective," Journal of Operations Management, 29 (6), 561-76. Watson, Forrest and Ahmet Ekici (2017), "Well-being in Alternative Economies: The Role of Shared Commitments in the Context of a Spatially-Extended Alternative Food Network," Journal of Macromarketing, 37 (2), 206-16.

Watts, David, Brian Ilbery, and Damian Maye (2005), "Making Reconnections in Agro-Food Geography: Alternative Systems of Food Provision," Progress in Human Geography, 29 (1), 22-40.

\section{Author Biographies}

Forrest Watson (PhD, Bilkent University) is an Assistant Professor of Marketing at Middle East Technical University. His research interests include quality of life, macromarketing, transformative consumer research, and social marketing.

Ahmet Ekici (PhD, University of Nebraska-Lincoln) is an Associate Professor of Marketing at Bilkent University. His main research areas are public policy and marketing; macromarketing and relationship marketing. His refereed articles have been published in a variety of journals including Journal of Macromarketing, Journal of Business Ethics, Industrial Marketing Management, Journal of Business Research, Journal of Public Policy \& Marketing, and Social Indicators Research. 